RESEARCH REPORT

\title{
Breast feeding and cardiovascular disease risk factors, incidence, and mortality: the Caerphilly study
}

\author{
Richard M Martin, Yoav Ben-Shlomo, David Gunnell, Peter Elwood, John W G Yarnell, \\ George Davey Smith
}

J Epidemiol Community Health 2005;59:121-129. doi: 10.1136/jech.2003.018952

See end of article for authors' affiliations

.....................

Correspondence to: Dr R M Martin,

Department of Social Medicine, University of Bristol, Canynge Hall,

Whiteladies Road, Bristol, BS8 2PR, UK; richard.martin@ bristol.ac.uk

Accepted for publication 26 March 2004

\begin{abstract}
Study objective: To investigate the association of having been breast fed with cardiovascular disease risk factors, incidence, and mortality.

Design: Prospective cohort study.

Setting: Caerphilly, South Wales.

Participants: All men aged 45-59 years living in and around the study area. Of 2818 eligible men, 2512 $(89 \%)$ were seen. Altogether 1580 men (63\%) obtained details of how they had been fed in infancy (ever breast fed or only bottle fed) from their mother or a close female relative. A subset of 1062 subjects reported on whether bottle fed or the duration of breast feeding if breast fed.

Main results: Breast feeding was not associated with stature, blood pressure, insulin resistance, total cholesterol, or fibrinogen. In fully adjusted models (controlling for age, birth order, and social position in childhood and adulthood), breast feeding was associated with greater body mass index than bottle feeding (difference: $0.41 \mathrm{~kg} / \mathrm{m}^{2}$ (95\% Cl: 0.01 to 0.81 ). There was a positive association between breast feeding and coronary heart disease mortality (hazard ratio: $1.73 ; 1.17$ to 2.55 ) and incidence (1.54; 1.17 to 2.04 ) (fully adjusted models). There was no evidence of a duration-response effect, which might be expected if an adverse effect of breast feeding was causal.

Conclusion: These data provide little evidence of a protective influence of breast feeding on cardiovascular disease risk factors, incidence, or mortality. A possible adverse effect of breast feeding on coronary heart disease incidence was observed but may have a number of explanations, including selection and information bias. In view of these limitations, further long term studies with improved measures of infant feeding are required to confirm or refute these findings.
\end{abstract}

T here is evidence that cardiovascular disease is influenced by exposures acting early in life. ${ }^{12}$ The role of prenatal factors is underlined by inverse associations of birth size and cardiovascular disease risk factors. ${ }^{2}$ An influence of postnatal exposures is suggested by inverse associations between cardiovascular disease mortality and height (a marker of adverse exposures during childhood ${ }^{3}$ ), which are independent of birth weight. ${ }^{45}$ In one study, family size was inversely associated with height in men from manual, but not non-manual families, pointing to a possible role for inadequate nutrition in vulnerable families. ${ }^{5}$ Leg length, a particularly sensitive marker of early nutrition and health, ${ }^{6}{ }^{7}$ is inversely associated with coronary heart disease risk..$^{8-11}$

Most studies investigating this issue have used indirect markers of childhood exposures (such as birth weight, height, and leg length). An association between leg length in childhood and breast feeding in infancy ${ }^{12}{ }^{13}$ persists after controlling for socioeconomic circumstances, suggesting that breast feeding may be a biologically relevant exposure underlying inverse associations of leg length with coronary heart disease risk. ${ }^{8-11}$

Breast feeding has been inversely associated with coronary heart disease mortality, except where it was prolonged $(\geqslant 1$ year $),{ }^{14}{ }^{15}$ as well as a number of risk factors, including obesity, ${ }^{16}$ dyslipidaemia, ${ }^{17}$ blood pressure, $^{18}{ }^{19}$ and insulin resistance. ${ }^{20}$ One study, however, found no association between breast feeding and coronary heart disease mortality, $^{22}$ and the possibility that breast feeding adversely influences cardiovascular outcomes has been raised. ${ }^{23} 24$ Here we relate breast feeding to cardiovascular disease risk factors, incidence, and mortality to determine if breast feeding is protective or detrimental to cardiovascular disease risk.

\section{METHODS}

The study is based on all men from Caerphilly who were aged 45-59 years when examined between 1979 to 1983. Of the 2818 eligible men, 2512 (89\%) were seen. Full details of the screening and follow up procedures have been reported elsewhere. ${ }^{525}$

\section{Infant feeding}

The men were asked to obtain from their mother, or a close female relative, details of how they had been fed as an infant. A total of 1580 men (63\%) gave information on whether they were only bottle fed or had received breast milk. A total of $1062(42 \%)$ men gave information on whether they were bottle fed or, if breast fed, duration of breast feeding. Duration of breast feeding was categorised as less than three months or at least three months so that comparisons could be made on the basis of feeding patterns reflecting the most common modern practice (about half of breast fed infants are still breast fed at three months, but only around one third continue to six months), ${ }^{26}$ and to permit comparison with key studies. ${ }^{27-32}$

\section{Clinic measurements}

Measurements included height, sitting height, weight, blood pressure, lipid profile, fibrinogen, insulin, glucose, own and father's occupational social class, place of birth, own employment, and smoking behaviour. Data from a self completed food frequency questionnaire have been used to 
estimate mean total fat, saturated fat, unsaturated fat, and energy intakes in adulthood. Self report birth weight data were available for $1258(50 \%)$ men. They were asked to obtain this information from their mother or close relative. Trunk length was calculated by subtracting the height of the stool from the recorded sitting height and leg length was calculated by subtracting trunk length from total standing height. Our index of adiposity was body mass index (weight $(\mathrm{kg}) /$ height $\left.(\mathrm{m})^{2}\right)$. Insulin resistance was estimated by homoeostasis model assessment (HOMA) as the product of fasting glucose $(\mathrm{mmol} / \mathrm{l})$ and insulin $(\mu \mathrm{U} / \mathrm{ml})$ divided by 22.5. ${ }^{33}$ HOMA was not calculated for subjects with a fasting glucose $\geqslant 7 \mathrm{mmol} / \mathrm{l}$ or those with a diagnosis of diabetes as the results are inaccurate in these groups.

\section{Cardiovascular morbidity and mortality}

The records of all men at the National Health Service Central Registry were flagged so that notification of death is automatic and a copy of the death certificate is received. Cause of death was defined by the International Classification of Diseases Ninth (ICD-9) Revision. Cardiovascular disease mortality was defined by ICD-9 codes: 390-459, coronary heart disease mortality by ICD-9 codes 410-414, deaths from stroke by ICD-9 codes 430-438. Incident non-fatal coronary heart disease and stroke were defined as in previous reports, ${ }^{54}{ }^{35}$ based on admission data to local hospitals, a self completed questionnaire regarding hospital admissions, and hospital discharge letters. Strokes were classified into ischaemic or haemorrhagic types as described previously. ${ }^{35}$ The results refer to mortality follow up to 31 December 2000 (a maximum of between 17.3 and 21.5 years of follow up) and for incident non-fatal coronary heart disease and stroke for an average of 15.8 and 16.0 years of follow up, respectively.

\section{Statistical methods}

The representativeness of subjects who provided data on method of infant feeding compared with those who did not was compared using $\chi^{2}$ tests. Associations of breast feeding with potential confounding variables were investigated using logistic regression. Survival analysis was performed using Cox's proportional hazards models, with bottle fed subjects as the reference group. Subjects who had been traced but for whom contact via the NHS central register had been lost, or who emigrated or died are included in the survival analysis and censored at the date of their last contact. As age is a strong determinant of mortality risk, and individuals entered the study at different ages, we controlled for current age in all models using age as the follow up time scale. We log transformed HOMA scores because of their skewed distribution. The geometric means are reported and the natural log used in regression models.

Multivariable models controlled additionally for own and father's social class, place of birth, birth order, smoking, and birth weight. The proportional hazards assumption was investigated by testing that the log hazard ratio is constant over time for each model. ${ }^{36}$ As breast feeding may interact with post-weaning saturated or unsaturated fat intake to influence the development of atherosclerosis, ${ }^{24}$ we tested for interaction between breast feeding and baseline body mass index (dichotomised at $25 \mathrm{~kg} / \mathrm{m}^{2}$ ), and intakes in adulthood of total fat, saturated fat, unsaturated fat, and energy (continuous variables adjusted for energy intake and dichotomised at the median) on cardiovascular disease risk using likelihood ratio tests. A proportion of subjects were born outside Caerphilly and may have experienced different infant feeding patterns, for example, with respect to exclusivity of breast feeding or alternatives to breast feeding. Changes in feeding patterns may have occurred over the range of year of births of the men (1918-1939). We therefore tested for interaction by place of birth and age at baseline.

The numbers of participants with information on each of the outcomes analysed varies slightly, and fewer participants had information on duration (compared with start) of breast feeding. Figure 1 shows the numbers of participants included in the final analytical models for each outcome.

To assess the possibility of selection bias, we compared the distributions of risk factors, incidence, and mortality, among those subjects whose feeding mode was unknown with those who were known to have been breast or bottle fed using analysis of variance or the log-rank test as appropriate. To assess the sensitivity of our conclusions to missing infant feeding data we repeated the analyses with inverse probability weighting. ${ }^{37}$ Using this method, observations are weighted by the inverse of the probability of observing a response. This gives greater weight in the analysis to subjects with an increased probability of missing observations and is based on developing a model predicting inclusion in the analysis. The weighted analysis was implemented by creating a binary response that was $\mathrm{l}$ if infant feeding data were present and 0 if missing. A logistic regression model was used to identify predictors of known infant feeding mode using as covariates the baseline variables in table 1. This model calculates the probability of an observation being present. Subject specific weights were calculated as the inverse of the fitted probabilities from the logistic regression model, normalised to sum to 1 . The analytical models were then refitted with the observed data weighted using these inverse probability weights. Analyses were performed using Stata 8.0 (College Station, TX: Stata Corporation, release 8.0, 2003).

\section{RESULTS}

The 1580 subjects included in this analysis contributed 26647 person years of follow up. A total of 1159 (73\%) were breast fed. Of the 684 breast fed subjects who knew their duration of breast feeding, $69 \%$ were breast fed for over three months. Subjects who provided data on method of infant feeding were heavier at birth (by $0.18 \mathrm{~kg}$ ) and younger at baseline than those who did not, were more likely to be from non-manual social backgrounds (in childhood and adulthood), and to be first or second born (table 1). The magnitude of these differences was comparatively small in absolute terms (maximum 9\% difference in any single category).

The proportion of subjects who had been breast fed increased with higher birth rank and age at baseline, and among those born outside the United Kingdom (table 2). Breast fed infants were $0.32 \mathrm{~kg}$ heavier at birth than those who were not $(p<0.001)$. There was little evidence that subjects who had been breast fed differed from those who had not according to their father's social class or unemployment status, or their own social class in adulthood.

\section{Stature and cardiovascular disease risk factors}

There was little evidence that breast feeding was associated with height, the components of height, blood pressure, insulin resistance, total cholesterol or fibrinogen in adulthood (table 3). In models controlling for age, social class in child and adulthood, and birth order breast fed infants had higher mean body mass index and low density lipoprotein cholesterol in adulthood than bottle fed infants (table 3). Controlling in addition for smoking status or place of birth made little difference to observed body mass index or low density lipoprotein cholesterol differences (data not shown). In the subset of subjects included in the final analysis with birth weight data $(n=1063)$, birth weight was only an important confounder of the association between breast feeding and body mass index (difference $\left(\mathrm{kg} / \mathrm{m}^{2}\right)$ in models 
2818

Potentially eligible participants

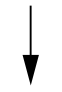

2512

Attended research clinic

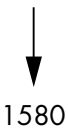

Provided information on method of infant feeding

Numbers included in the final analytical models by outcome investigated

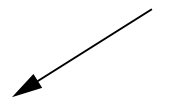

Stature and cardiovascular disease risk factors

\begin{tabular}{lcc}
\hline & \multicolumn{2}{c}{ Numbers } \\
\cline { 2 - 3 } & $\begin{array}{c}\text { Ever } \\
\text { breast fed versus } \\
\text { bottle fed }\end{array}$ & $\begin{array}{c}\text { Duration of } \\
\text { breast feeding }\end{array}$ \\
\hline Height & 1557 & 1051 \\
Leg length & 1531 & 1038 \\
Trunk length & 1539 & 1043 \\
$\begin{array}{l}\text { Systolic BP } \\
\text { Diastolic BP }\end{array}$ & 1576 & 1061 \\
BMI & 1572 & 1058 \\
Insulin & 1556 & 1051 \\
resistance & 1343 & 906 \\
Total & 1538 & 1034 \\
cholesterol & 1507 & 1013 \\
LDL- & & 1048 \\
cholesterol & 1560 & \\
Fibrinogen & & \\
\hline
\end{tabular}

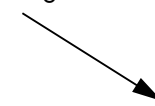

Incidence and mortality

\begin{tabular}{lcc}
\hline & \multicolumn{2}{c}{ Numbers } \\
\cline { 2 - 3 } & $\begin{array}{c}\text { Ever } \\
\text { breast fed versus } \\
\text { bottle fed }\end{array}$ & $\begin{array}{c}\text { Duration of } \\
\text { breast feeding* }\end{array}$ \\
\hline All deaths & $1578^{\ddagger}$ & 1060 \\
CVD deaths & $1578^{\ddagger}$ & 1060 \\
CHD deaths & $1578^{\ddagger}$ & 1060 \\
Incident & $1578^{\ddagger}$ & 1060 \\
CHD & $1578^{\ddagger}$ & 1060 \\
$\begin{array}{l}\text { Stroke } \\
\text { deaths }\end{array}$ & $1565^{ף}$ & $1056^{\S}$ \\
Incident & & \\
strokes & & \\
\hline
\end{tabular}

controlling for age and social factors: 0.49 (95\% CI: -0.01 to $0.90)$; in models also controlling for birth weight: $0.34(-0.16$ to 0.84$)$ ).

\section{Cardiovascular disease incidence and mortality}

Breast feeding was not associated with all cause mortality (table 4). There was, respectively, a 54\% (95\% CI: $17 \%$ to $104 \%)$ and $73 \%$ (17\% to $155 \%)$ increase in coronary heart disease incidence and mortality associated with breast feeding (fully adjusted models). There was weak evidence of a $44 \%$ reduction in stroke mortality associated with breast feeding $(p=0.13)$ but no association with all incident strokes. There was little evidence of an association between breast feeding and incident ischaemic strokes $(n=121$; hazard ratio in fully adjusted model: $1.14 ; 95 \%$ CI: 0.74 to 1.74). Hazard ratios were little changed $(<5 \%)$ when the models in table 4 were further controlled for place of birth, smoking, body mass index, total fat, saturated fat, unsaturated fat, or energy intake in adulthood, in addition to age and social factors (data not shown). In subjects with birth weight data $(\mathrm{n}=1077)$, there was no evidence that birth weight confounded associations between breast feeding and all cause or cause specific mortality.

There was no evidence of a duration-response relation for most of the outcomes studied, except for an increasing body mass index associated with a longer duration of breast feeding (change in body mass index per change in breast feeding category: $0.32 \mathrm{~kg} / \mathrm{m}^{2} ; 95 \%$ CI: 0.07 to 0.56 ) (table 5 ).
Figure 1 Numbers of participants who were: eligible to participate in the study, attended the research clinic, provided information on method of infant feeding and, for each of the outcomes investigated, were included in the final analytical models for associations between breast fed compared with bottle fed and duration of breast feeding. BP, blood pressure; BMI, body mass index; LDL, low density lipoprotein; CVD, cardiovascular disease; CHD, coronary heart disease. *Fewer subjects had information on duration of breast feeding than on if it was started. ${ }^{\dagger}$ Excludes subjects with diabetes. ${ }^{\ddagger}$ Two of the 1580 subjects were lost to further follow up with no subsequent contact after the first clinic. "Two of the 1580 subjects were subsequently lost to further follow up and 13 had a prior history of stroke. ${ }^{\S}$ Four of the 1060 subjects had a prior history of stroke.
There was little evidence for interaction by body mass index in adulthood on the associations between breast feeding and coronary heart disease mortality $(p=0.3)$, all incident coronary heart disease $(p=0.4)$, stroke mortality $(\mathrm{p}=0.8)$, or all incident strokes $(\mathrm{p}=0.3)$. There was little evidence for interaction by total fat intake in adulthood on the associations between breast feeding and coronary heart disease mortality $(p=0.6)$, all incident coronary heart disease $(p=0.9)$, stroke mortality $(p=0.9)$, or all incident strokes $(p=0.7)$. There was little evidence for interaction by age, place of birth, social class in child or adulthood, birth order, saturated or unsaturated fat intake in adulthood on any of the cardiovascular disease outcomes studied.

\section{Outcomes by knowledge of infant feeding mode}

Tables 3 and 4 show that those men who did not know how they were fed in infancy were shorter with respect to total height $(p=0.0005)$, leg length $(p=0.004)$, and trunk length $(p=0.01)$, and had higher rates of cardiovascular disease $(\mathrm{p}=0.01)$, and coronary heart disease mortality $(0.003)$ and incidence $(p=0.01)$, than those who reported infant feeding mode. The groups were similar with respect to blood pressure, insulin resistance, lipid profile, fibrinogen, all cause and stroke events $(p \geqslant 0.2)$. When the mortality and cardiovascular disease incidence analyses were re-weighted to allow for missing data, the observed effect sizes were little changed. 


\begin{tabular}{|c|c|c|c|}
\hline Variable & $\begin{array}{l}\text { Breast feeding } \\
\text { status known (\%) }\end{array}$ & $\begin{array}{l}\text { Breast feeding status } \\
\text { unknown }(\%)\end{array}$ & $\mathrm{p}$ Value \\
\hline \multicolumn{4}{|c|}{ Social class in childhood } \\
\hline Non-manual & 13 & 10 & \\
\hline Manual & 87 & 90 & \\
\hline Number* & 1521 & 771 & 0.02 \\
\hline \multicolumn{4}{|l|}{ Birth order } \\
\hline First & 31 & 26 & \\
\hline Second & 24 & 22 & \\
\hline Third & 15 & 14 & \\
\hline Fourth or more & 30 & 38 & \\
\hline Number* & 1570 & 822 & $<0.001$ \\
\hline \multicolumn{4}{|l|}{ Father unemployed } \\
\hline No & 56 & 51 & \\
\hline Yes & 44 & 49 & \\
\hline Number* & 1332 & 579 & 0.05 \\
\hline \multicolumn{4}{|l|}{ Birth place } \\
\hline Caerphilly & 50 & 52 & \\
\hline Other UK & 47 & 46 & \\
\hline Outside UK & 3 & 2 & \\
\hline Number* ${ }^{*}$ & 1578 & 839 & 0.2 \\
\hline \multicolumn{4}{|c|}{ Social class in adulthood } \\
\hline Non-manual & 35 & 26 & \\
\hline Manual & 65 & 74 & \\
\hline Number* & 1541 & 904 & $<0.001$ \\
\hline \multicolumn{4}{|l|}{ Smoking history } \\
\hline Never & 27 & 24 & \\
\hline Ex smoker & 30 & 28 & \\
\hline Current smoker & 43 & 48 & \\
\hline Number* & 1574 & 927 & 0.07 \\
\hline \multicolumn{4}{|c|}{ Age at baseline examination } \\
\hline 44 to 49 & 36 & 28 & \\
\hline 50 to 54 & 31 & 34 & \\
\hline$>55$ over & 33 & 38 & \\
\hline Number* & 1580 & 932 & $<0.001$ \\
\hline Birth weight, kg & $3.65(0.86)$ & $3.47(0.88)$ & 0.009 \\
\hline Number* & 1079 & 179 & \\
\hline
\end{tabular}

*The number in each category varies as some subjects had missing data. †Based on $\chi^{2}$ test for categorical variables and unpaired $t$ test for birth weight.

\section{DISCUSSION}

Although several reports suggest that breast feeding is favourably associated with cardiovascular disease risk, ${ }^{16} 2021$ meta-analyses show that effects sizes are small, and that publication bias and socioeconomic confounding are an important concern. ${ }^{17} 18$ The strength of this study is that there was little evidence of any social patterning of breast feeding, as would be expected in the UK before the second world war. ${ }^{38}$ This suggests that our results are less likely than some reports ${ }^{1621}$ to be explained by uncontrolled socioeconomic confounding. There was evidence that patterns of breast feeding changed between 1918 to 1939 , as a higher prevalence of breast feeding was observed in men over 50 years at initial examination (table 2), but associations did not differ according to age at baseline.

We found that breast feeding was associated with an increased risk of coronary heart disease. There was no evidence, however, of a duration-response relation, which might be expected if there was a biological mechanism underlying an adverse effect of breast feeding on coronary heart disease. Before discussing the implications of these findings it is important to assess limitations that may have given rise to these associations.

\section{Limitations}

Firstly, the positive breast feeding-coronary heart disease association might have arisen if the $37 \%$ of the study population who were excluded from the analysis because of missing information on infant feeding mode contained a high proportion of bottle fed subjects with increased death rates from coronary heart disease compared with those who were included in the study. In a prospective validation study comparing information recalled in adulthood with that recorded in infancy, bottle fed subjects were more likely not to know how they had been fed in infancy compared with breast fed subjects. ${ }^{39}$ This evidence, combined with our finding that men who did not report their infant feeding method had higher rates of coronary heart disease, suggest the possibility of selection bias. Effect sizes were little changed, however, when analyses were re-weighted to account for missing data on infant feeding mode, although this model assumes the data were missing at random. Furthermore, even if all those with missing data $(\mathrm{n}=932)$ were bottle fed, the positive association between breast feeding and coronary heart disease deaths would not be completely abolished (risk ratio: 1.06; 95\% CI: 0.85 to 1.33).

Secondly, a related weakness of the study is that measurement of infant feeding, among those giving this information, relied on recall after several decades. The impact of this limitation is difficult to assess. On the one hand, studies have shown the validity ${ }^{40}$ and reliability ${ }^{41}{ }^{42}$ of long term recall of infant feeding method. Moreover, strengths of the study were that method of infant feeding was obtained from the mother, and cardiovascular disease was measured prospectively. Thus misclassification bias may be nondifferential, attenuating our effect estimates and masking any true associations, rather than producing spurious associations. On the other hand, differential recall of breast feeding status by social position has previously been noted, ${ }^{43}$ and may have occurred in this study. If people from less 


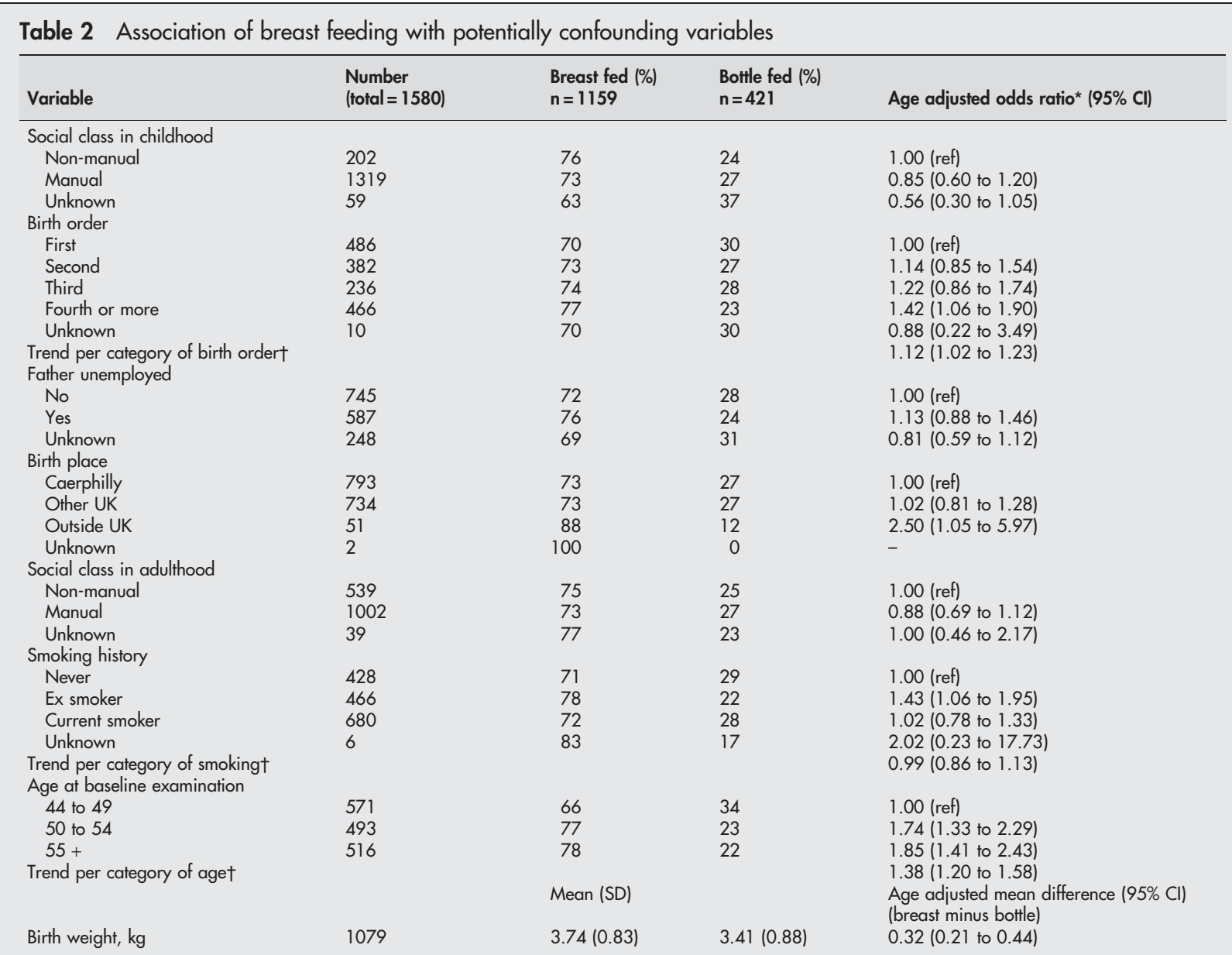

*Odds ratios give odds of being breast fed in each strata of variable compared with reference stratum. $†$ Trend per category of variable gives increase in odds ratio for each increase in category of ordinal variable (excluding unknown).

affluent social classes (who are at increased risk of coronary heart disease) were more likely to state they had been breast fed when they had in fact been bottle fed, this may explain the positive association between breast feeding and coronary heart disease. The rate of breast feeding $(73 \%)$ was similar to breast feeding rates $(70 \%-85 \%)$ in contemporaneous reports, ${ }^{13}{ }^{38}$ giving some reassurance about the validity of the infant feeding data.

Thirdly, we had no information on exclusivity of breast feeding and were unable to investigate whether results differ among infants who were exclusively or partially breast fed, as has been suggested in other studies. ${ }^{21}$

Fourthly, an influence of breast feeding in humans may depend on later dietary patterns, ${ }^{24}$ which are now very different to those in the early 20 th century. ${ }^{44}$ We could not assess post-weaning diet directly, but we found no evidence of interaction by body mass index or fat intake in adulthood on breast feeding-coronary heart disease associations, which may have been observed if a long term effect of breast feeding depended on later diet.

Fifthly, age at introduction of solids is a possible confounding factor. However, a number of studies have suggested that age at weaning has little impact on certain cardiovascular risk factors, such as obesity ${ }^{45}$ and blood pressure levels, ${ }^{27}{ }^{46}$ and a review of several studies showed that few infants were introduced to solids before 6-9 months in the 1920s and 1930s. ${ }^{47}$ The importance of age at weaning as a confounding factor is unclear.

Finally, the alternatives to breast feeding in this pre-war cohort included packaged preparations of cereals, wheat, and flour made up with milk, condensed and fresh cow's milk. ${ }^{38}$ These preparations differ substantially from the nutrient content of modern formulas, which now more closely resemble breast milk. ${ }^{48}$ Distinct associations with particular types of infant formula feeds may produce different results in contemporary cohorts.

\section{Comparison with other studies}

Few studies have examined the association between breast feeding and atherosclerosis. ${ }^{14} 224950$ In line with our findings, a small $(\mathrm{n}=160)$, postmortem study of children and young adults (2-30 years) who had died suddenly showed more coronary artery plaques among those who had been breast fed for at least four weeks (16\%) compared with those never breast fed (5\%), ${ }^{49}$ although breast fed subjects were slightly older and interpretation is hampered by failure to adjust for age. Data from the Hertfordshire cohort suggested that exclusive breast feeding prolonged for over one year may be detrimental to coronary heart disease risk. ${ }^{14}$ In a small cross sectional study ( $\mathrm{n}=331)$ among young adults born between 1969-1975, arterial stiffness (suggested as a predictor of coronary heart disease) was associated with duration of breast feeding. ${ }^{23}$ This report is limited by retrospective assessment of breast feeding and uncertainty over the clinical relevance of arterial stiffness.

In contrast, an earlier postmortem study in young adults found lower rates of coronary atheroma among those breast fed $(25 \%)$ compared with those artificially fed $(60 \%)$ in infancy. ${ }^{51}$ A small case-control study showed no association between breast feeding and myocardial infarction, ${ }^{50}$ and a 

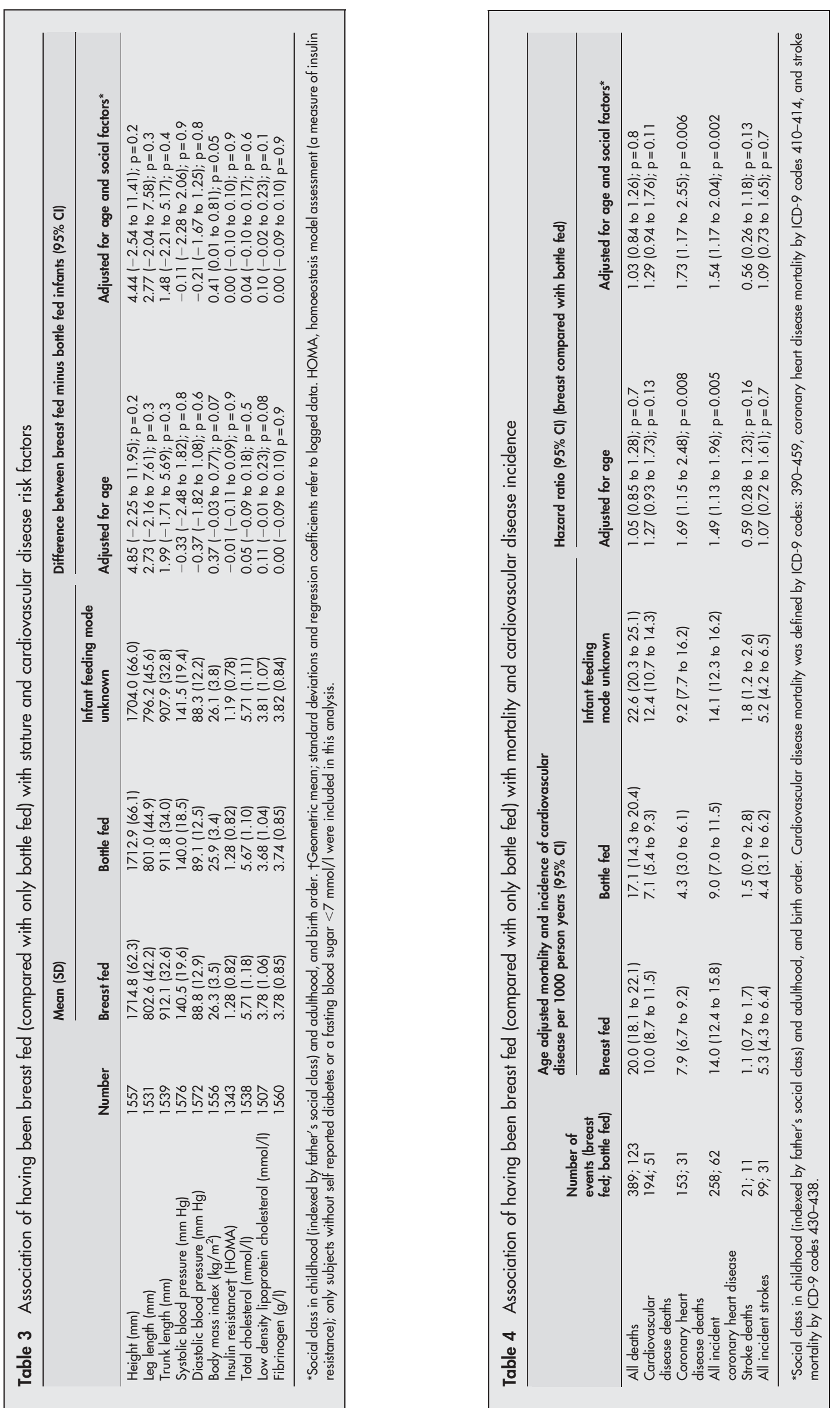
Table 5 Association of breast feeding duration with stature and cardiovascular disease risk factors, incidence, and mortality

\begin{tabular}{|c|c|c|c|c|c|}
\hline & & $\begin{array}{l}\text { Never } \\
\text { breast fed }\end{array}$ & $\begin{array}{l}\text { Breast fed for } \\
1-3 \text { months }\end{array}$ & $\begin{array}{l}\text { Breast fed for } \\
>3 \text { months }\end{array}$ & Trendt \\
\hline & Number in analysis & \multicolumn{4}{|c|}{ Difference between breast fed minus bottle fed infants $(95 \% \mathrm{Cl})^{*}$} \\
\hline Height (mm) & 1051 & 0.00 (ref) & $1.81(-8.57$ to 12.20$)$ & $4.77(-3.63$ to 13.17$)$ & $2.40(-1.79$ to 6.59$) ; p=0.3$ \\
\hline Leg length (mm) & 1038 & 0.00 (ref) & $2.63(-4.50$ to 9.77$)$ & $1.88(-3.90$ to 7.66$)$ & $0.90(-1.99$ to 3.78$) ; p=0.5$ \\
\hline Trunk length $(\mathrm{mm})$ & 1043 & 0.00 (ref) & $-0.84(-6.38$ to 4.71$)$ & $2.18(-2.32$ to 6.68$)$ & $1.13(-1.11$ to 3.38$) ; p=0.3$ \\
\hline Systolic BP (mm Hg) & 1061 & 0.00 (ref) & $-0.08(-3.29$ to 3.13$)$ & $-0.04(-2.64$ to 2.57$)$ & $-0.02(-1.32$ to 1.28$) ; p=0.9$ \\
\hline Diastolic BP (mm Hg) & 1058 & 0.00 (ref) & $-0.55(-2.72$ to 1.61$)$ & $0.42(-1.34$ to 2.17$)$ & $0.23(-0.65$ to 1.10$) ; p=0.6$ \\
\hline Body mass index & 1051 & 0.00 (ref) & $0.24(-0.36$ to 0.84$)$ & $0.63(0.14$ to 1.12$)$ & $0.32(0.07$ to 0.56$) ; p=0.01$ \\
\hline Insulin resistance† (HOMA) & 906 & 0.00 (ref) & $0.09(-0.06$ to 0.25$)$ & $0.00(-0.13$ to 0.12$)$ & $0.00(-0.06$ to 0.06$) ; p=0.9$ \\
\hline Total cholesterol (mmol/l) & 1034 & 0.00 (ref) & $0.17(-0.02$ to 0.37$)$ & $0.03(-0.14$ to 0.19$)$ & $0.01(-0.07$ to 0.09$) ; p=0.8$ \\
\hline $\begin{array}{l}\text { Low density lipoprotein } \\
\text { cholesterol (mmol/l) }\end{array}$ & 1013 & 0.00 (ref) & $0.18(0.00$ to 0.36$)$ & $0.07(-0.08$ to 0.22$)$ & $0.03(-0.04$ to 0.10$) ; p=0.4$ \\
\hline \multirow[t]{4}{*}{ Fibrinogen (g/l) } & 1048 & 0.00 (ref) & $-0.04(-0.18$ to 0.10$)$ & $-0.03(-0.15$ to 0.08$)$ & $-0.02(-0.07$ to 0.04$) ; p=0.6$ \\
\hline & Number of events & & & & \\
\hline & $\begin{array}{l}\text { (never BF; } \\
\mathrm{BF} \leqslant 3 \text { months; }\end{array}$ & \multirow{2}{*}{\multicolumn{4}{|c|}{ Hazard ratio $(95 \% \mathrm{Cl})^{*}$}} \\
\hline & $\mathrm{BF}>3$ months) & & & & \\
\hline All deaths & $111 ; 68 ; 141$ & 1.00 (ref) & 1.08 (0.80 to 1.47$)$ & 0.95 (0.74 to 1.22$)$ & $0.97(0.86$ to 1.10$) ; p=0.7$ \\
\hline Cardiovascular disease deaths & $46 ; 32 ; 60$ & 1.00 (ref) & $1.23(0.78$ to 1.94$)$ & 1.01 (0.68 to 1.48$)$ & $1.00(0.83$ to 1.21$) ; p=0.9$ \\
\hline Coronary heart disease deaths & $30 ; 26 ; 47$ & 1.00 (ref) & 1.60 (0.94 to 2.72$)$ & $1.25(0.79$ to 1.98$)$ & $1.10(0.88$ to 1.37$) ; p=0.4$ \\
\hline $\begin{array}{l}\text { All incident coronary heart } \\
\text { disease }\end{array}$ & $58 ; 44 ; 90$ & 1.00 (ref) & $1.41(0.95$ to 2.09$)$ & $1.24(0.89$ to 1.73$)$ & $1.10(0.94$ to 1.29$) ; p=0.2$ \\
\hline Stroke deaths & $7 ; 3 ; 8$ & 1.00 (ref) & 0.76 (0.19 to 3.01$)$ & $0.73(0.26$ to 2.06$)$ & $0.85(0.51$ to 1.44$): p=0.6$ \\
\hline All incident strokes & $26 ; 17 ; 33$ & 1.00 (ref) & $1.14(0.61$ to 2.12$)$ & $0.96(0.57$ to 1.62$)$ & $0.98(0.76$ to 1.26$) ; p=0.9$ \\
\hline \multicolumn{6}{|c|}{$\begin{array}{l}\text { BP, blood pressure; HOMA, homoeostasis model assessment (a measure of insulin resistance); BF, breast fed. *Fully adjusted models, controlling for age and socia } \\
\text { class in childhood (indexed by father's social class) and adulthood, and birth order. TTrend gives mean difference of change in hazard of outcome per increase in } \\
\text { category of breast feeding duration. Cardiovascular disease mortality was defined by ICD-9 codes: } 390-459 \text {, coronary heart disease mortality by ICD-9 codes } \\
410-414 \text {, and stroke mortality by ICD-9 codes } 430-438 \text {. Mortality analysis was based on } 1060 \text { subjects with data on method of infant feeding and duration o } \\
\text { breast feeding. }\end{array}$} \\
\hline
\end{tabular}

Californian cohort $(\mathrm{n}=1373$ ) born between 1904-1915 found no association between breast feeding assessed at age 11 years and cardiovascular disease (hazard ratios: 1.04 for men and 1.07 for women) or coronary heart disease (data not given) mortality in a 65 year follow up study. ${ }^{22}$

Our findings support a recent systematic review showing little evidence of any strong association between breast feeding and blood pressure. ${ }^{18}$ As in some studies, ${ }^{39} 5253$ breast feeding was associated with greater adiposity, although the absolute size of the effect was small and may have been confounded by birth weight. While several studies report a protective effect of breast feeding on adiposity ${ }^{16}{ }^{32}$ others show that this association is inconsistent or disappears after controlling for important confounding factors. ${ }^{54}$

Our finding of no association between breast feeding and insulin resistance is in line with a cross sectional study from

\section{Key points}

- The literature on the association between infant feeding method and future cardiovascular disease risk is limited by publication bias and inadequate control for socioeconomic confounding

- We investigated the relation between breast feeding and cardiovascular disease risk factors, incidence, and mortality in a cohort of men born when the maternal decision to breast feed was not socially patterned

- Breast feeding was not associated with stature, blood pressure, insulin resistance, total cholesterol, or fibrinogen in adulthood, but was associated with greater body mass index compared with bottle feeding

- There was a positive association between breast feeding and coronary heart disease incidence but this finding may have a number of explanations, including selection and information bias
France showing no difference in blood glucose levels in breast and formula fed children. ${ }^{55}$ Others, in contrast, show improved glucose tolerance ${ }^{20}$ and reduced type 2 diabetes ${ }^{21}$ associated with breast feeding. These studies were in selected populations (infants exposed to the Dutch famine and Pima Indians respectively) and may not be generalisable. The increased low density lipoprotein cholesterol associated with breast feeding concurs with findings for prolonged breast feeding in the Hertfordshire cohort, ${ }^{14}$ but contrasts with most studies in adults. ${ }^{17}$ Discrepancies may have arisen as a result of differences in the alternatives to breast feeding, chance, or residual confounding. ${ }^{17}$

\section{CONCLUSION}

The idea that infant feeding method influences cardiovascular disease risk has attracted increasing interest in the literature, ${ }^{17}{ }^{18}$ possibly because of the potential to identify novel potential preventative interventions that could be started early in life.

We found a positive association between breast feeding and coronary heart disease incidence, as shown in some studies. ${ }^{142349}$ This finding may be explained by the limitations of the study, such as selection or information bias. It is clear, however, that our study provides no support for a cardioprotective effect of breast feeding into later life. Breast milk contains a number of anti-inflammatory, hormonal, and growth factors that are not found in formula feeds, and animal and human studies suggest that breast feeding may lead to permanent changes in physiology and

\section{Policy implication}

Breast feeding should continue to be the preferred method of infant nutrition, based on its established psychological, cognitive, and health benefits, but not because it may be cardioprotective in adulthood 
metabolism. ${ }^{17} 20245657$ At the older ages that our study outcomes were measured, any influence of breast feeding may be masked by other causal pathways operating later in life. Further investigation of the metabolic and other physiological effects of breast feeding in children and young adults may therefore still provide clues about mechanisms linking early life exposures with later health. Meanwhile, breast feeding remains the preferred method of infant feeding for at least four to six months of life, based on its beneficial influences on infectious diseases, psychosocial, and cognitive development, and the absence of evidence of adverse effects on child health. ${ }^{58}$

\section{ACKNOWLEDGEMENTS}

RMM was supported by a Wellcome Trust Research Training Fellowship in Clinical Epidemiology (grant number: GR063779MA). The Caerphilly study was conducted by the former MRC Epidemiology Unit (South Wales) and was funded by the Medical Research Council of the United Kingdom. The archive is now maintained by the Department of Social Medicine in the University of Bristol. We thank the staff at the NHS Central Register, Southport, who notify deaths and cancer registrations to the research team.

\section{CONTRIBUTORS}

RMM, YBS, PE, GDS, and DG developed the hypothesis. PE and JWGY undertook the original fieldwork and designed the questionnaires. RMM did the analysis, wrote the first draft of the paper, and coordinated completion. All authors contributed and approved the final version.

\section{Authors' affiliations}

R M Martin, Yoav Ben-Shlomo, David Gunnell, G Davey Smith, Department of Social Medicine, University of Bristol, Bristol, UK P Elwood, Department of Epidemiology, Statistics and Public Health University of Wales, College of Medicine, Cardiff, Wales J W G Yarnell, Department of Epidemiology and Public Health, Queen's University of Belfast, $\mathrm{N}$ Ireland

Conflicts of interest: none declared.

\section{REFERENCES}

Kuh D, Ben-Shlomo Y. A life course approach to chronic disease epidemiology. Oxford: OUP, 1997.

2 Barker DJP. Fetal and infant origins of adult disease. London: BMJ Books, 1992.

3 Eveleth PB, Tanner JM. Worldwide variation in human growth. London: Cambridge University Press, 1976.

4 Rich-Edwards JW, Manson JE, Stampfer MJ, et al. Height and the risk of cardiovascular disease in women. Am J Epidemiol 1995;142:909-17.

5 Yarnell JGW, Limb ES, Layzell JM, et al. Height: a risk marker for ischaemic heart disease: prospective results from the Caerphilly and Speedwell heart disease studies. Eur Heart J 1992;13:1602-5.

6 Gunnell D. Can adult anthropometry be used as a biomarker for prenatal and childhood exposures? Int J Epidemiol 2002;31:390-4

7 Gunnell DJ, Davey Smith G, Frankel SJ, et al. Socio-economic and dietary influences on leg length and trunk length in childhood: a reanalysis of the Carnegie (Boyd Orr) survey of diet and health in prewar Britain (1937-39). Paediatr Perinat Epidemiol 1998;12(suppl 1):96-113.

8 Davey Smith G, Greenwood R, Gunnell D, et al. Leg length, insulin resistance, and coronary heart disease risk: the Caerphilly study. J Epidemiol Community Health 2001;55:867-72

9 Gunnell DJ, Davey Smith G, Frankel S, et al. Childhood leg length and adult mortality: follow-up study of the Carnegie (Boyd Orr) survey of diet and health in pre-war Britain. J Epidemiol Community Health 1998;52:142-52.

10 Lawlor DA, Ebrahim S, Davey Smith G. The association between components of adult height and type II diabetes and insulin resistance: British women's heart and health study. Diabetologia 2002;45:1097-106.

11 Lawlor DA, Davey Smith G, Ebrahim S. Life course influences on insulin resistance: findings from the British women's heart and health study. Diabetes Care 2003;26:97-103.

12 Wadsworth ME, Hardy RJ, Paul AA, et al. Leg and trunk length at 43 years in relation to childhood health, diet and family circumstances; evidence from the 1946 national birth cohort. Int J Epidemiol 2002;31:383-90.

13 Martin RM, Davey Smith G, Mangtani P, et al. Association between breast feeding and growth: the Boyd-Orr cohort study. Arch Dis Child Fetal Neonatal Ed 2002;87:F193-201

14 Fall CHD, Barker DJP, Osmond C, et al. Relation of infant feeding to adult serum cholesterol concentration and death from ischaemic heart disease. BMJ 1992;304:801-5
15 Osmond C, Barker DJP, Winter PD, et al. Early growth and death from cardiovascular disease in women. BMJ 1993;307:1519-24.

16 Von Kries R, Koletzko B, Sauerwald T, et al. Breast feeding and obesity: cross sectional study. BMJ 1999;319:147-50.

17 Owen CG. Whincup PH, Odoki K, et al. Infant feeding and blood cholesterol: a study in adolescents and a systematic review. Pediatrics 2002;1 10:597-608.

18 Owen CG, Whincup PH, Gilg JA, et al. Effect of breast feeding in infancy on blood pressure in later life: systematic review and meta-analysis. BMJ 2003:327:1189-95.

19 Martin RM, McCarthy A, Davies DP, et al. Association between infant nutrition and blood pressure in early adulthood: the Barry Caerphilly growth cohort study. Am J Clin Nutr 2003;77:1489-97.

20 Ravelli ACJ, van der Meulen JH, Osmond C, et al. Infant feeding and adult glucose tolerance, lipid profile, blood pressure, and obesity. Arch Dis Child 2000;82:248-52

21 Pettitt DJ, Forman MR, Hanson RL, et al. Breastfeeding and incidence of noninsulin-dependent diabetes mellitus in Pima Indians. Lancet 1997;350:166-8.

22 Wingard DL, Criqui MH, Edelstein SL, et al. Is breast-feeding associated with adult longevity? Am J Public Health 1994;84:1458-62.

23 Leeson CP, Kattenhorn M, Deanfield JE, et al. Duration of breast feeding and arterial distensibility in early adult life: population based study. BMJ 2001;322:643-7.

24 Lewis DS, Mott GE, McMahan CA, et al. Deferred effects of preweaning diet on atherosclerosis in adolescent baboons. Arteriosclerosis 1988;8:274-80.

25 The Caerphilly and Speedwell Collaborative Group. Caerphilly and Speedwell collaborative heart disease studies. J Epidemiol Community Health 1984; 38:259-62.

26 Foster K, Lader D, Cheesborough S. Infant feeding 1995: a survey of infant feeding practices in the United Kingdom carried out by the Social Survey Division of ONS on behalf of the Department of Health, the Scottish Office Department of Health, the Welsh Office and the Department of Health and Social Services in Northern Ireland. London: The Stationery Office, 1997.

27 Wilson AC, Forsyth JS, Greene SA, et al. Relation of infant diet to childhood health: seven year follow up of cohort of children in Dundee infant feeding study. BMJ 1998;316:21-5.

28 Tulldahl J, Pettersson K, Andersson SW, et al. Mode of infant feeding and achieved growth in adolescence: early feeding patterns in relation to growth and body composition in adolescence. Obes Res 1999;7:431-7.

29 Whincup PH, Cook DG, Shaper AG. Early influences on blood pressure: a study of children aged 5-7 years. BMJ 1989;299:587-91.

30 Taittonen L, Nuutinen $M$, Turtinen J, et al. Prenatal and postnatal factors in predicting later blood pressure among children: cardiovascular risk in young Finns. Pediatr Res 1996;40:627-32.

31 Elliott KG, Kjolhede CL, Gournis E, et al. Duration of breastfeeding associated with obesity during adolescence. Obes Res 1997:5:538-41.

32 Bergmann KE, Bergmann RL, Von Kries R, et al. Early determinants of childhood overweight and adiposity in a birth cohort study: role of breastfeeding. Int J Obes 2003;27:162-72.

33 Matthews DR, Hosker JP, Rudenski AS, et al. Homeostasis model assessment: insulin resistance and beta-cell function from fasting plasma glucose and insulin concentrations in man. Diabetologia 1985;28:412-19.

34 Elwood PC, Beswick A, Pickering J, et al. Platelet tests in the prediction of myocardial infarction and ischaemic stroke: evidence from the Caerphilly prospective study. Br J Haematol 2001;113:514-20.

35 Fallon UB, Elwood P, Ben Shlomo Y, et al. Homocysteine and ischaemic stroke in men: the Caerphilly study. J Epidemiol Community Health 2001;55:91-6.

36 StataCorp. Stata survival analysis and epidemiological tables. Reference manual release 8.0. College Station, TX: Stata Corporation, 2003.

37 Ziegler A, Kastner C, Chang-Claude J. Analysis of pregnancy and other factors on detection of human papilloma virus (HPV) infection using weighted estimating equations for follow-up data. Stat Med 2003;22:2217-33.

38 Fildes V. Infant feeding practices and infant mortality in England, 1900-1919. Continuity and Change 1998;13:251-80.

39 Marmot MG, Page CM, Atkins E, et al. Effect of breast feeding on plasma cholesterol and weight in young adults. J Epidemiol Community Health 1980;34:164-71.

40 Kark JD, Troya G, Friedlander Y, et al. Validity of maternal reporting history and the association with blood lipids in 17 year olds in Jerusalem. J Epidemiol Community Health 1984;38:218-25.

41 Tomeo CA, Rich-Edwards JW, Michels KB, et al. Reproducibility and validity of maternal recall of pregnancy-related events. Epidemiology $1999 ; 10: 774-7$.

42 Haaga JG. Reliability of retrospective survey data on infant feeding. Demography 1988;25:307-14.

43 Vobecky JS, Vobecky J, Froda S. The reliability of the maternal memory in a retrospective assessment of nutritional status. J Clin Epidemiol 1988;41:261-5.

44 Maynard M. Diet in childhood and risk of adult cancer. [PhD thesis]. Bristol: University of Bristol, 2000.

45 Kramer MS. Does breast-feeding and delayed introduction of solid foods protect against subsequent obesity? J Pediatr 1981;98:883-7.

46 Boulton J. Nutrition in childhood and its relationships to early somatic growth, body fat, blood pressure, and physical fitness. Acta Paediatr Scand Suppl 1981;284:1-85.

47 MRC. Infant nutrition and cardiovascular disease. Scientific report no 8. Southampton: MRC Environmental Epidemiology Unit, 1987.

48 Anonymous. Artificial feeds for the young infant. Report of the Working Party on the Composition of Foods for Infants and Young Children, Committee on Medical Aspects of Food Policy. Reports on Health and Social Subjects $2001 ; 18: i-v i i i$. 
49 Burr ML, Beasley WH, Fisher CB. Breast feeding, maternal smoking and early atheroma. Eur Heart J 1984;5:588-91.

50 Cowen DD. Myocardial infarction and infant feeding. Practitioner 1973;210:661-3.

51 Osborn GR. Stages in development of coronary disease observed from 1500 young subjects: relationship of hypotension and infant feeding to aetiology. Colloques Internationaux du Centre National de la Recherche Scientifique 1967;169:93-139

52 Wadsworth M, Marshall S, Hardy R, et al. Breast feeding and obesity: relation may be accounted for by social factors. BMJ 1999;319:1576.

53 Agras WS, Kraemer HC, Berkowitz RI, et al. Influence of early feeding style on adiposity at 6 years of age. J Pediatr 1990;116:805-9.
54 Clifford TJ. Breast feeding and obesity. BMJ 2003:327:879-80.

55 Plancoulaine S, Charles MA, Lafay L, et al. Infant-feeding patterns are related to blood cholesterol concentration in prepubertal children aged $5-11$ y: the Fleurbaix-Laventie Ville Sante study. Eur J Clin Nutr 2000;54:114-19.

56 Singhal A, Cole TJ, Lucas A. Early nutrition in preterm infants and later blood pressure: two cohorts after randomised trials. Lancet 2001;357:413-19.

57 Singhal A, Fewtrell M, Cole TJ, et al. Low nutrient intake and early growth for later insulin resistance in adolescents born preterm. Lancet 2003;361:1089-97.

58 Kramer MS, Kakuma R. The optimal duration of exclusive breastfeeding: a systematic review. Geneva: World Health Organisation, 2002.

\section{Clinical Evidence-Call for contributors}

Clinical Evidence is a regularly updated evidence-based journal available worldwide both as a paper version and on the internet. Clinical Evidence needs to recruit a number of new contributors. Contributors are healthcare professionals or epidemiologists with experience in evidence-based medicine and the ability to write in a concise and structured way.

Areas for which we are currently seeking authors:

- Child health: nocturnal enuresis

- Eye disorders: bacterial conjunctivitis

- Male health: prostate cancer (metastatic)

- Women's health: pre-menstrual syndrome; pyelonephritis in non-pregnant women

However, we are always looking for others, so do not let this list discourage you.

Being a contributor involves:

- Selecting from a validated, screened search (performed by in-house Information Specialists) epidemiologically sound studies for inclusion.

- Documenting your decisions about which studies to include on an inclusion and exclusion form, which we keep on file.

- Writing the text to a highly structured template (about 1500-3000 words), using evidence from the final studies chosen, within 8-10 weeks of receiving the literature search.

- Working with Clinical Evidence editors to ensure that the final text meets epidemiological and style standards.

- Updating the text every six months using any new, sound evidence that becomes available. The Clinical Evidence in-house team will conduct the searches for contributors; your task is simply to filter out high quality studies and incorporate them in the existing text.

- To expand the topic to include a new question about once every 12-18 months.

If you would like to become a contributor for Clinical Evidence or require more information about what this involves please send your contact details and a copy of your CV, clearly stating the clinical area you are interested in, to Klara Brunnhuber (kbrunnhuber@ bmigroup.com).

\section{Call for peer reviewers}

Clinical Evidence also needs to recruit a number of new peer reviewers specifically with an interest in the clinical areas stated above, and also others related to general practice. Peer reviewers are healthcare professionals or epidemiologists with experience in evidence-based medicine. As a peer reviewer you would be asked for your views on the clinical relevance, validity, and accessibility of specific topics within the journal, and their usefulness to the intended audience (international generalists and healthcare professionals, possibly with limited statistical knowledge). Topics are usually 1500-3000 words in length and we would ask you to review between 2-5 topics per year. The peer review process takes place throughout the year, and our turnaround time for each review is ideally 10-14 days.

If you are interested in becoming a peer reviewer for Clinical Evidence, please complete the peer review questionnaire at www.clinicalevidence.com or contact Klara Brunnhuber (kbrunnhuber@bmigroup.com). 